\title{
Efeito residual de fertilizantes fosfatados solúveis na recuperação de pastagem de Brachiaria brizantha cv. Marandu em Neossolo Quartzarênico ${ }^{1}$
}

\author{
Patrícia Perondi Anchão Oliveira ${ }^{2}$, Wladecir Salles de Oliveira ${ }^{3}$, Moacyr Corsi $^{4}$
}

\author{
1 Trabalho financiado pela empresa Fertilizantes Mitsui Indústria e Comércio. Bolsas de estudo financiadas pela FAPESP. \\ ${ }^{2}$ EMBRAPA/Pecuária Sudeste. \\ ${ }^{3}$ Monsanto Agroscience. \\ ${ }^{4}$ ESALQ/USP.
}

\begin{abstract}
RESUMO - Dois experimentos foram realizados, por um período de dois anos, para avaliar a resposta de um sistema solo-pastagem a fertilizantes fosfatados de diferentes velocidades de solubilização (superfosfato simples, superfosfato triplo e termofosfato magnesiano) associados ou não à calagem. Não houve diferença em produção de forragem entre as várias fontes de fósforo, quando as adubações fosfatadas foram feitas nos dois anos. A associação de fertilizantes pode ser vantajosa, porque o termofosfato promoveu as maiores produções de forragem quando se suprimiu a adubação fosfatada no segundo ano, enquanto as adubações com superfosfatos resultaram nas maiores produções no primeiro ano. A calagem favoreceu a produção de forragem e proporcionou aumento nos teores de nutrientes e redução do alumínio no solo. A resposta à adubação foi melhor no segundo ano, porque a pastagem estava em recuperação.
\end{abstract}

Palavras-chave: degradação, fontes, fósforo, solo cerrado, termofosfato

\section{Residual effect of soluble phosphorus fertilizers on pasture recovery (Brachiaria brizantha cv. Marandu) in sandy soil}

\begin{abstract}
Two experiments were conducted during two years for evaluation of the soil/pasture system response to phosphorus fertilizers with different solubilization rates (ordinary superphosphate, triple superphosphate, and termalphosphate), with and without liming. The various phosphorus sources did not affect forage yield when fertilization was made during two years. Association of fertilizers may be advantageous since termalphosphate promoted the best forage yield when phosphorus fertilization was suppressed in the second year while fertilization with superphosphates resulted in best forage yield in the first year. Liming favored forage yield allowing higher nutrient concentration and reduction of aluminum in the soil. Response to fertilization was better in the second year because the pasture was under recovery.
\end{abstract}

Key Words: Cerrado soil, degradation, phosphorus, sources, termalphosphate

\section{Introdução}

As pastagens, apesar de constituírem a base de exploração do sistema de produção de bovinos no Brasil, ocupam várias extensões de solos de cerrado, com reconhecidas limitações em fertilidade (Lopes, 1984). Destaca-se a deficiência de fósforo como uma das formas mais restritivas para a pecuária, considerando-se que as pastagens são relativamente mais exigentes em $P$ que as culturas anuais, em razão da maior produção de massa seca, extração e exportação de nutrientes (Goedert \& Lobato, 1984). Além da baixa disponibilidade de fósforo, o uso de fertilizações fosfatadas em cerrado complica-se pelo fato desses solos apresentarem elevada capacidade de adsorção do fosfato e acidez, fato que proporciona a transformação do fósforo solúvel em água em formas não-disponíveis para planta, como o fosfato de ferro e o fosfato de alumínio (Büll et al., 1997; Nakayama et al., 1998).

Os termofosfatos são fertilizantes silicatados, o que pode ser uma vantagem em solos de cerrado. Os silicatos, por competirem com os sítios de adsorção de fósforo, contribuem para a manutenção do P em sua forma lábil (Büll et al., 1997), podendo fornecer maior quantidade de fósforo disponível para plantas em condições adversas ao uso de fertilizantes solúveis em água. Este fato é importante porque, em pastagens estabelecidas sobre solos bastante ácidos, mesmo quando se realiza a calagem, há dificuldade em se atingirem valores adequados de saturação por bases nos primeiros anos de correção do solo (Oliveira et al., 2003). 
Em razão dessas diferenças nos padrões de disponibilização e fixação de fósforo, espera-se que os termofosfatos apresentem um efeito residual no fornecimento de fósforo às plantas. Na última década, foram conduzidos alguns trabalhos com o objetivo de avaliar este efeito para culturas anuais (Büll et al., 1997; Rossi et al., 1999).

Para pastagens, somente o comportamento de fosfatos de baixa solubilidade nacional e dos superfosfatos, solúveis em água, foram bem definidos em experimentos a campo conduzidos por longos períodos (Goedert \& Lobato, 1984). Já as informações sobre a fertilização em pastagens com fontes solúveis em ácido cítrico, como os fosfatos naturais e os termofosfatos, carecem de mais estudos.

Este trabalho foi desenvolvido visando-se avaliar a resposta de um sistema solo-pastagem a fontes de fertilizantes fosfatados de diferentes solubilidades associados ou não à calagem.

\section{Material e Métodos}

Foram realizados dois experimentos na Fazenda Mercedes localizada no município de Descalvado, SP, com coordenadas geográficas 21057' 05"S e 47037' 26"W e altitude de $679 \mathrm{~m}$, durante dois anos. A área experimental constituiu-se de pastagem degradada de Brachiaria brizantha cv. Marandu estabelecida em Neossolo Quartzarênico, com pH em $\mathrm{CaCl}_{2}=4,0 ; \mathrm{MO}=20 \mathrm{~g} \mathrm{dm}^{-3}$; $\mathrm{P}=1 \mathrm{mg} \mathrm{dm}^{-3}$; e 0,$8 ; 2 ; 1 ; 12 ;$ mmol $_{\mathrm{C}} \mathrm{dm}^{-3}$ de K, Ca, Mg e Al, respectivamente; saturação por bases de 7\%; saturação por alumínio de $76 \%$ e S $\left(\mathrm{Ca}\left(\mathrm{H}_{2} \mathrm{PO}_{4}\right)_{2}\right)=1 \mathrm{mg} \mathrm{dm}^{-3}$, conforme Camargo et al. (1986).

No primeiro experimento, adotou-se delineamento experimental de blocos casualizados em estrutura fatorial, com quatro repetições, em que foram avaliadas três fontes de fertilizantes fosfatados (termofosfato magnesiano, superfosfato simples e superfosfato triplo) e duas correções do solo (ausência de correção do solo e calagem para atingir a saturação por bases de 70\%), além de tratamento adicional testemunha (pastagem degradada). No segundo experimento, utilizou-se o mesmo delineamento experimental, entretanto, a fertilização fosfatada foi suprimida no segundo ano com o objetivo de se avaliar o efeito residual das diferentes fontes de fertilizantes fosfatados (Tabela 1 ).

As parcelas (2 m x $5 \mathrm{~m}$ ) foram instaladas no campo, em julho de 1998, aplicando-se calcário dolomítico PRNT 90 na dose de 4,5 t/ha. Em novembro de 1998, foi realizado um corte de uniformização a $0,20 \mathrm{~m}$ de altura realizando-se a primeira de quatro fertilizações. As doses de nutrientes aplicados foram de $80 \mathrm{~kg} \mathrm{ha}^{-1}$ de $\mathrm{P}_{2} \mathrm{O}_{5}$ da fonte de fertilizante requerida por tratamento, $30 \mathrm{~kg} \mathrm{ha}^{-1}$ de micronutrientes na forma de FTE BR $12^{\circledR}, 274 \mathrm{~kg} \mathrm{ha}^{-1}$ de $\mathrm{K}_{2} \mathrm{O}$ na forma de cloreto de potássio, suficiente para atingir 5\% de K na CTC, utilizando-se eficiência de $70 \%, 280 \mathrm{~kg} \mathrm{ha}^{-1} \mathrm{de} \mathrm{N}$, na forma de uréia ou sulfato de amônio, conforme tratamento, e $53 \mathrm{~kg} \mathrm{ha}^{-1}$ de $\mathrm{S}$ na forma de superfosfato simples ou enxofre elementar ou sulfato de amônio, também conforme cada tratamento, com o objetivo de aplicar a mesma quantidade de enxofre em todos os tratamentos. O conteúdo total de $\mathrm{P}$, $\mathrm{S}$ e micronutrientes foi aplicado na primeira fertilização. $\mathrm{O}$ $\mathrm{K}_{2} \mathrm{O}$ foi parcelado nas duas primeiras fertilizações e o $\mathrm{N}$, em quatro fertilizações, a cada 35 dias, no período de novembro de 1998 a março de 1999.

Em julho de 1999, realizou-se novamente a calagem para atingir a saturação por bases de $70 \%$, segundo resultados médios da análise de solo para cada tratamento ao final do primeiro ano. Em novembro de 1999, iniciaram-se novamente as fertilizações de cobertura. Para o experimento 1, as doses de fertilizantes foram de $80 \mathrm{~kg} \mathrm{ha}^{-1}$ de $\mathrm{P}_{2} \mathrm{O}_{5}$, na forma requerida por tratamento, $30 \mathrm{~kg} \mathrm{ha}^{-1} \mathrm{de}$ micronutrientes na forma de FTE BR $12^{\circledR}, 53 \mathrm{~kg} \mathrm{ha}^{-1}$ de S

Tabela 1 - Tratamentos dos experimentos 1 (fertilização com P durante dois anos) e 2 (efeito residual, fertilização com P somente no primeiro ano)

Table 1 - Treatments of the experiment 1 ( $P$ fertilization during two years) and experiment 2 (residual effect, $P$ fertilization only in the first year)

\begin{tabular}{|c|c|c|c|c|c|}
\hline \multirow{2}{*}{\multicolumn{2}{|c|}{$\begin{array}{l}\text { Dose } \mathrm{P} / \text { fertilização }\left(\mathrm{P}_{2} \mathrm{O}_{5} \mathrm{~kg} \mathrm{ha}^{-1} \mathrm{ano}^{-1}\right) \\
P \text { rate/fertilization }\left(\mathrm{P}_{2} \mathrm{O}_{5} \mathrm{~kg} \mathrm{ha^{-1 } \text { year }} \text { ) }\right.\end{array}$}} & \multirow[t]{2}{*}{$\begin{array}{c}\text { Fonte de } \mathrm{P} \\
P \text { source }\end{array}$} & \multirow[t]{2}{*}{$\begin{array}{l}\text { Calagem } \\
\text { Liming }\end{array}$} & \multicolumn{2}{|c|}{$\begin{array}{l}\text { № fertilizações com } \mathrm{P} \\
N \text {. of fertilizations with } P\end{array}$} \\
\hline & & & & Exp. 1 & Exp. 2 \\
\hline Testemunha (control) ${ }^{1}$ & & Sem & Sem & 0 & 0 \\
\hline 80 & Super & simples (Superphosphate) & + & 2 & 1 \\
\hline 80 & Super & triplo (Triple superphosphate) & + & 2 & 1 \\
\hline 80 & Term & o magnesiano (Magnesium termophosphate) & + & 2 & 1 \\
\hline 80 & Super & simples (Superphosphate) & - & 2 & 1 \\
\hline 80 & Super & triplo (Triple superphosphate) & - & 2 & 1 \\
\hline 80 & Term & o magnesiano (Magnesium termophosphate) & - & 2 & 1 \\
\hline
\end{tabular}

\footnotetext{
1 Testemunha composta por pastagem degradada (Degraded control).

+ (presença); - (ausência).
}

+ (presence); - (ausence). 
na forma de superfosfato simples ou enxofre elementar ou sulfato de amônio conforme cada tratamento, cloreto de potássio, suficiente para atingir 5\% de K na CTC, utilizando-se eficiência de $70 \%$ e $280 \mathrm{~kg} \mathrm{ha}^{-1}$ de N, na forma de uréia ou sulfato de amônio, conforme tratamento. O conteúdo total de P, S e micronutrientes foi aplicado na primeira fertilização, em novembro de 1999. $\mathrm{O} \mathrm{K}_{2} \mathrm{O}$ foi parcelado nas duas primeiras fertilizações e o N, em quatro fertilizações, a cada 35 dias, no período de novembro de 1999 a março de 2000.

No segundo ano para o experimento 2, adotaram-se os mesmos procedimentos do experimento 1 , mas não foi realizada a fertilização com fósforo, no sentido de avaliar o efeito residual das diferentes fontes de fertilizantes.

Os cortes da estação chuvosa (entre novembro e abril) foram realizados a cada 35 dias e os da estação seca (entre maio e outubro), a cada 60 dias, conforme avaliação visual da senescência das folhas da planta forrageira, totalizando seis cortes da forrageira no ano agrostológico de 1998/1999 e sete cortes em 1999/2000. A altura de corte foi de $20 \mathrm{~cm}$. A produção de massa seca da parte aérea foi obtida por meio do corte manual de quatro subamostras de $0,3 \mathrm{~m} \times 0,6 \mathrm{~m}$ tomadas ao acaso em cada parcela. Em outubro de cada ano, foi avaliado o resíduo de forragem existente na área. Nos meses de janeiro e julho, as quatro subamostras de cada parcela foram compostas para análise dos teores de N, P, S. No final do período experimental, em novembro de 2000 , foram colhidas amostras para análise do teor de Si na planta forrageira.

Em cortes alternados e durante todo o período experimental, foi avaliada a produção de massa seca de raízes por meio de amostragem com sonda, separando-se (lavagem em peneira de 20 mesh) as raízes do solo. As amostras foram secas a $65^{\circ} \mathrm{C}$ durante 48 horas. $\mathrm{O}$ acompanhamento da fertilidade de solo foi realizado nas profundidades de $0-0,05 \mathrm{~m}$, 0,05-0,10 m e 0,10-0,20 m, em junho de 1999, e ao final do período experimental (novembro de 2000), ocasião em que foi avaliada a infestação por micorrizas no sistema radicular. Foram realizadas determinações dos cátions trocáveis e P, utilizando-se a resina trocadora, conforme Camargo et al. (1986). O pH foi determinado em $\mathrm{CaCl}_{2}\left(0,01 \mathrm{~mol} \mathrm{~L}^{-1}\right)$.

Foram realizadas a análise de variância e a aplicação do teste F para os tratamentos que compuseram o fatorial, considerando-se os anos experimentais como fator.

\section{Resultados e Discussão}

Não houve interação calagem $\times$ fonte de fósforo sobre a produção de forragem para os dois experimentos, nos dois anos de avaliação.

Quando houve suprimento de fósforo nos dois anos, totalizando $160 \mathrm{~kg} \mathrm{ha}^{-1}$ de $\mathrm{P}_{2} \mathrm{O}_{5}$, a fonte de fertilizante fosfatado não interferiu na produção média anual de massa de forragem (Tabela 2), evidenciando que o termofosfato possui eficiência semelhante à das fontes solúveis em água (superfosfato simples e superfosfato triplo), conforme observado por Rossi et al. (1999), Nakayama et al. (1998) e Büll, et al. (1997). Entretanto, quando se realizou uma única fertilização fosfatada, visando-se avaliar o efeito residual, verificou-se que, no primeiro ano, o superfosfato triplo proporcionou maior produção de massa de $B$. brizantha que o termofosfato magnesiano. O superfosfato simples proporcionou produção intermediária entre as duas fontes. No segundo ano, o termofosfato magnesiano proporcionou as melhores produções de massa seca, o superfosfato simples as menores e o superfosfato triplo as intermediárias. A maior produção dos superfosfatos no primeiro ano deve-se à rápida disponibilidade de $\mathrm{P}$ proporcionada por estas fontes, que são solúveis em água. A menor produção dos superfosfatos no segundo ano, também observada em outros trabalhos (Moreira et al., 1997), pode ser atribuída à fixação do fósforo solúvel no solo, diminuindo sua disponibilidade à planta, enquanto a maior produção obtida com o uso de termofosfato pode estar associada à liberação mais lenta do fósforo e à presença dos silicatos no termofosfato que competem com fosfatos pelos sítios de adsorção do solo, fatos que induzem a menores taxas de fixação (Büll et al., 1997).

A calagem acarretou aumento de produção de forragem quando foi suprimida a aplicação de fósforo no segundo ano (Tabela 2), evidenciando o efeito da calagem em melhorar a disponibilidade de nutrientes em condições de limitações nutricionais.

A produção de forragem foi maior no segundo ano (Tabela 2) para os dois experimentos, concordando com os resultados de Oliveira et al. (2005) e Cunha et al. (2001). Como as condições climáticas foram semelhantes nos dois anos (Figura 1), a melhor resposta em produtividade da B. brizantha está ligada à melhor eficiência de uso de nutrientes e ao aumento das estruturas produtivas após o processo de recuperação da pastagem, conforme observado por Oliveira et al.(2003) e Oliveira \& Corsi (2001).

Para a produção de raízes, não houve interação dos fatores estudados (calagem, fonte de fósforo e tempo) para ambos os experimentos, nos quais a quantidade de raízes aumentou na camada de 0-0,05 m, manteve-se estável na de 0,05-0,10 m e diminuiu na de 0,10-0,30 m do primeiro para o segundo ano (Tabela 3). Este comportamento pode estar associado à forma de aplicação do calcário e dos fertilizantes aplicados na superfície do solo, favorecendo o aumento do sistema radicular na superfície do solo.

A calagem promoveu aumento de $\mathrm{P}$ na planta no período da seca. No período das águas do experimento com 
Tabela 2 - Produção anual de forragem de B. brizantha durante dois anos Table 2 - Annual forage production of the B. brizantha during two years

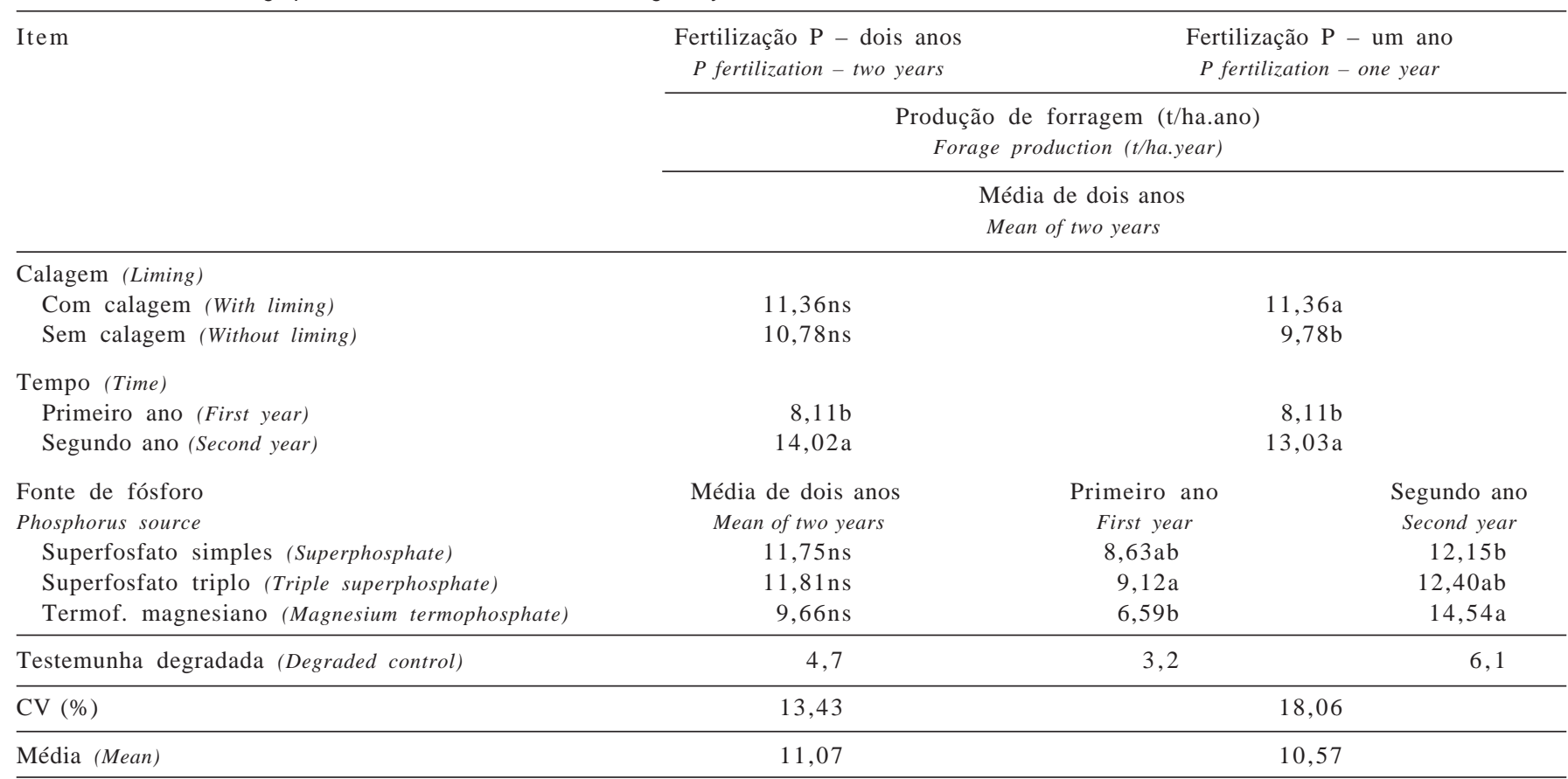

Médias seguidas por diferentes letras, dentro da mesma coluna, são diferentes $(P<0,05)$ pelo teste Tukey.

Means followed by different letter, within a column, are different $(P<0.05)$ by Tukey test.

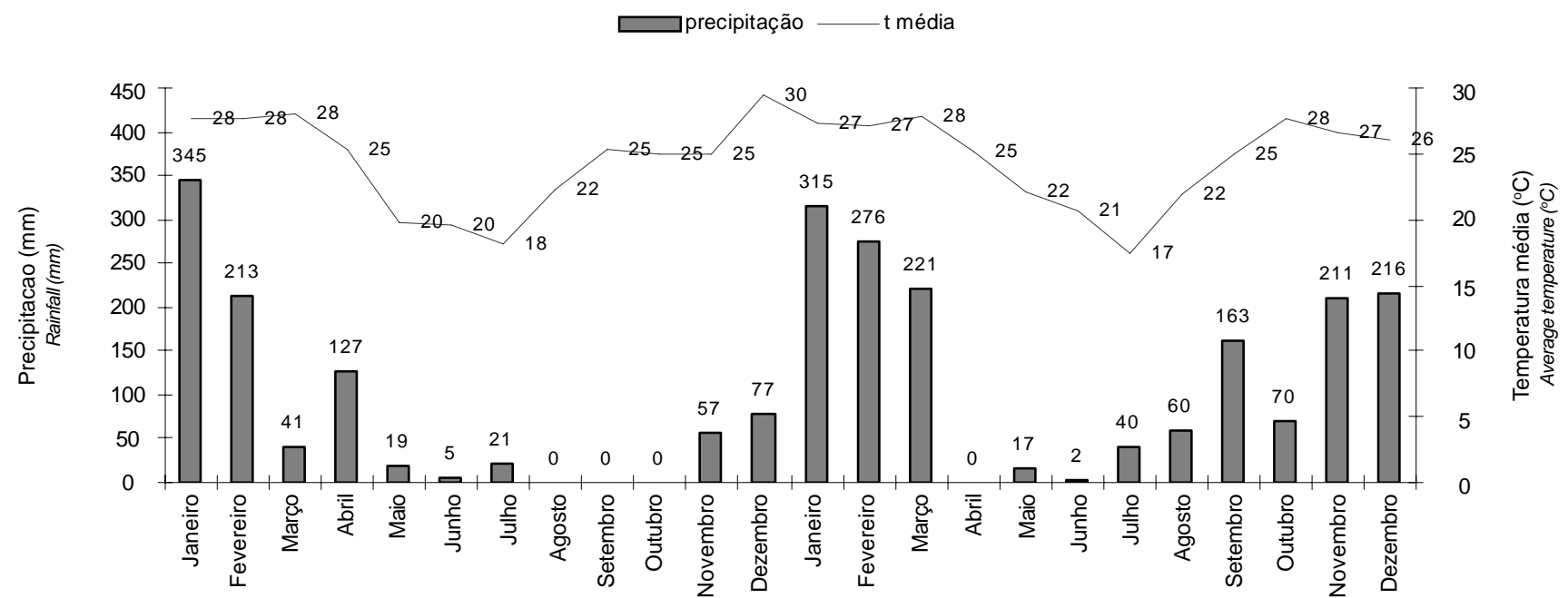

Figura 1 - Condições climatológicas na área experimental em Descalvado, SP.

Figure 1 - Climate conditions in the experimental area, Descalvado, SP.

fosfatagem nos dois anos e na seca do experimento com fosfatagem em apenas um ano houve efeito das fontes de $\mathrm{P}$ empregadas. Os teores de $\mathrm{P}$ na planta foram maiores quando se utilizou superfosfato triplo em relação ao uso do termofosfato magnesiano. Os teores de P na planta foram intermediários para o superfosfato simples, elevando-se, em todas as situações, do primeiro para o segundo ano (Tabela 4).

O teor de $\mathrm{N}$ na planta durante a seca do experimento com supressão de $\mathrm{P}$ foi menor quando houve aplicação de calagem (Tabela 5). Do primeiro para o segundo ano, houve queda nos teores de $\mathrm{N}$ nos dois experimentos e em todas as épocas do ano, provavelmente em decorrência do aumento de produção da forragem, causando o efeito de diluição.

O superfosfato simples - uma das fontes de fósforo tradicionalmente usada nas pastagens - fornece não só o fósforo, mas também o enxofre. Dada a importância do enxofre na formação de proteínas para pastagens, principalmente pela relação $\mathrm{N}: \mathrm{S}$, deve haver compensação das doses de enxofre quando ocorre a substituição do superfosfato 
Tabela 3 - Quantidade de raízes de $B$. brizantha em diferentes profundidades em dois anos Table 3 - $\quad$ Amount of roots of B. brizantha in different depths in two years

\begin{tabular}{|c|c|c|c|c|c|c|}
\hline \multirow[t]{3}{*}{ Item } & \multicolumn{6}{|c|}{$\begin{array}{l}\text { Experimento } \\
\text { Experiment }\end{array}$} \\
\hline & \multicolumn{3}{|c|}{$\begin{array}{c}\text { Fertilização } \mathrm{P}-\text { dois anos } \\
P \text { fertilization - two years }\end{array}$} & \multicolumn{3}{|c|}{$\begin{array}{c}\text { Fertilização com P - um ano } \\
\text { P fertilization - one year }\end{array}$} \\
\hline & \multicolumn{6}{|c|}{$\begin{array}{c}\text { Raízes }(\mathrm{t} / \mathrm{ha}) / \text { Profundidade }(\mathrm{cm}) \\
\text { Roots }(\mathrm{t} / \mathrm{ha}) / \text { Depth }(\mathrm{cm})\end{array}$} \\
\hline \multicolumn{7}{|l|}{ Calagem } \\
\hline \multicolumn{7}{|l|}{ Liming } \\
\hline $\begin{array}{l}\text { Com calagem } \\
\text { With liming }\end{array}$ & $5,18 \mathrm{~ns}$ & $3,47 \mathrm{~ns}$ & $5,07 \mathrm{~ns}$ & $5,05 \mathrm{~ns}$ & 3,73ns & $4,81 \mathrm{~ns}$ \\
\hline $\begin{array}{l}\text { Sem calagem } \\
\text { Without liming }\end{array}$ & $5,09 \mathrm{~ns}$ & $2,89 \mathrm{~ns}$ & $5,29 \mathrm{~ns}$ & $4,98 \mathrm{~ns}$ & $3,51 \mathrm{~ns}$ & $5,07 \mathrm{~ns}$ \\
\hline $\begin{array}{l}\text { Superfosfato triplo } \\
\text { Triple superphosphate }\end{array}$ & $5,15 \mathrm{~ns}$ & $3,03 \mathrm{~ns}$ & $5,39 \mathrm{~ns}$ & $5,75 a$ & $3,78 \mathrm{~ns}$ & $5,18 \mathrm{~ns}$ \\
\hline $\begin{array}{l}\text { Termofosfato magnesiano } \\
\text { Magnesium termophosphate }\end{array}$ & 4,53ns & $2,86 \mathrm{~ns}$ & $4,77 \mathrm{~ns}$ & $4,32 b$ & $3,62 \mathrm{~ns}$ & $4,80 \mathrm{~ns}$ \\
\hline \multicolumn{7}{|l|}{ Tempo } \\
\hline \multicolumn{7}{|l|}{ Time } \\
\hline $\begin{array}{l}\text { Primeiro ano } \\
\text { First year }\end{array}$ & $4,54 b$ & 3,30ns & $5,76 a$ & $4,54 b$ & $3,30 \mathrm{~ns}$ & $5,76 a$ \\
\hline $\begin{array}{l}\text { Segundo ano } \\
\text { Second year }\end{array}$ & $5,74 a$ & $3,07 \mathrm{~ns}$ & $4,59 b$ & $5,49 a$ & $3,94 \mathrm{~ns}$ & $4,12 b$ \\
\hline CV (\%) & 31,3 & 35,1 & 34,1 & 27,5 & 36,8 & 35,2 \\
\hline
\end{tabular}

Médias seguidas por diferentes letras, dentro da mesma coluna, são diferentes $(P<0,05)$ pelo teste Tukey.

Means followed by different letters, within a column, are different $(P<0.05)$ by Tukey test.

Tabela 4 - Teor de P na parte aérea de Brachiaria brizantha cv. Marandu

Table 4 - $\quad$ Average P concentration in the shoot of Brachiaria brizantha cv. Marandu

\begin{tabular}{|c|c|c|c|c|}
\hline \multirow[t]{2}{*}{ Item } & \multicolumn{2}{|c|}{$\begin{array}{c}\text { Fertilização } \mathrm{P}-\text { dois anos } \\
P \text { fertilization - two years }\end{array}$} & \multicolumn{2}{|c|}{$\begin{array}{c}\text { Fertilização } \mathrm{P} \text { - um ano } \\
P \text { fertilization - one year }\end{array}$} \\
\hline & \multicolumn{4}{|c|}{$\begin{array}{l}\text { Teor de } \mathrm{P}(\mathrm{g} / \mathrm{kg}) \\
P \text { concentration }(\mathrm{g} / \mathrm{kg})\end{array}$} \\
\hline \multicolumn{5}{|l|}{ Calagem (Liming) } \\
\hline $\begin{array}{l}\text { Com calagem (With liming) } \\
\text { Sem calagem (Without liming) }\end{array}$ & $\begin{array}{l}2,46 \mathrm{~ns} \\
2,38 \mathrm{~ns}\end{array}$ & $\begin{array}{l}1,07 \mathrm{a} \\
0,89 \mathrm{~b}\end{array}$ & $\begin{array}{l}2,19 \mathrm{~ns} \\
2,11 \mathrm{~ns}\end{array}$ & $\begin{array}{l}1,22 \mathrm{a} \\
1,10 \mathrm{~b}\end{array}$ \\
\hline $\begin{array}{l}\text { Fonte de P (P source) } \\
\text { Superfosfato simples (Superphosphate) } \\
\text { Superfosfato triplo (Triple superphosphate) } \\
\text { Termofosfato magnesiano (Magnesium termophosphate) }\end{array}$ & $\begin{array}{r}2,48 a b \\
2,58 a \\
2,21 b\end{array}$ & $\begin{array}{l}0,95 \mathrm{~ns} \\
1,08 \mathrm{~ns} \\
0,92 \mathrm{~ns}\end{array}$ & $\begin{array}{l}2,22 \mathrm{~ns} \\
2,21 \mathrm{~ns} \\
2,01 \mathrm{~ns}\end{array}$ & $\begin{array}{r}1,16 a b \\
1,24 a \\
1,08 b\end{array}$ \\
\hline $\begin{array}{l}\text { Tempo (Time) } \\
\text { Primeiro ano (First year) } \\
\text { Segundo ano (Second year) }\end{array}$ & $\begin{array}{l}1,96 \mathrm{~b} \\
2,89 \mathrm{a}\end{array}$ & $\begin{array}{l}0,70 \mathrm{~b} \\
1,27 \mathrm{a}\end{array}$ & $\begin{array}{l}1,99 \mathrm{~b} \\
2,31 \mathrm{a}\end{array}$ & $\begin{array}{l}0,67 \mathrm{~b} \\
1,65 \mathrm{a}\end{array}$ \\
\hline Média (Mean) & 2,4 & 0,98 & 2,15 & 1,16 \\
\hline
\end{tabular}

Médias seguidas por diferentes letras, dentro da mesma coluna, são diferentes $(P<0,05)$ pelo teste Tukey.

Means followed by different letters, within a column, are different $(P<0.05)$ by Tukey test. 
Tabela 5 - Teor de N na parte aérea de Brachiaria brizantha cv. Marandu

Table 5 - $\quad N$ concentration in the shoot of Brachiaria brizantha cv. Marandu

\begin{tabular}{|c|c|c|c|c|}
\hline \multirow[t]{3}{*}{ Item } & \multicolumn{2}{|c|}{$\begin{array}{c}\text { Fertilização } P \text { - dois anos } \\
P \text { fertilization - two years }\end{array}$} & \multicolumn{2}{|c|}{$\begin{array}{l}\text { Fertilização } \mathrm{P} \text { - um ano } \\
P \text { fertilization - one year }\end{array}$} \\
\hline & \multicolumn{4}{|c|}{$\begin{array}{c}\text { Teor de N (g/kg) } \\
N \text { concentration }(g / k g)\end{array}$} \\
\hline & $\begin{array}{c}\text { Águas } \\
\text { Rainy season }\end{array}$ & $\begin{array}{c}\text { Seca } \\
\text { Dry season }\end{array}$ & $\begin{array}{l}\text { Águas } \\
\text { Rainy season }\end{array}$ & $\begin{array}{c}\text { Seca } \\
\text { Dry season }\end{array}$ \\
\hline Sem calagem (Without liming) & $20,04 \mathrm{~ns}$ & $9,15 \mathrm{~ns}$ & $20,03 \mathrm{~ns}$ & $9,15 a$ \\
\hline \multicolumn{5}{|l|}{ Fonte de $\mathrm{P}(P$ source $)$} \\
\hline Superfosfato simples (Superphosphate) & $19,94 \mathrm{~ns}$ & $8,84 \mathrm{~ns}$ & $19,37 \mathrm{~ns}$ & $8,63 n s$ \\
\hline Superfosfato triplo (Triple superphosfate) & $20,44 \mathrm{~ns}$ & $9,17 \mathrm{~ns}$ & $20,13 n s$ & $9,06 \mathrm{~ns}$ \\
\hline Termofosfato magnesiano (Magnesium termophosphate) & $19,56 \mathrm{~ns}$ & $8,78 \mathrm{~ns}$ & $19,55 \mathrm{~ns}$ & $8,77 \mathrm{~ns}$ \\
\hline Testemunha degradada (Degraded control) & 18,23 & 8,38 & 17,33 & 8,03 \\
\hline Média (Mean) & 19,98 & 8,93 & 19,68 & 8,82 \\
\hline
\end{tabular}

Médias seguidas por diferentes letras, dentro da mesma coluna, são diferentes $(P<0,05)$ pelo teste Tukey.

Means followed by different letters, within column, are different $(P<0.05)$ by Tukey test.

simples por outra fonte de fósforo. Neste trabalho, para o tratamento com superfosfato simples, a compensação foi realizada pelo uso de sulfato de amônio em parte da cobertura nitrogenada e, no caso do termofosfato magnesiano, houve adição de enxofre ao fertilizante. Essas substituições da fonte de enxofre não afetaram os teores de $\mathrm{S}$ na parte aérea da forragem. Entretanto, no experimento com fosfatagem nos dois anos, houve interação calagem $\times$ fonte de fósforo no período das águas, em que o tratamento calagem com a fonte superfosfato simples apresentou teor de $\mathrm{S}$ superior ao do tratamento sem calagem com a mesma fonte de fósforo. Possivelmente, parte do S ficou indisponível à planta, em decorrência da acidez do solo na ausência da calagem.

Não houve influência dos fatores estudados sobre teor de silício na planta (Tabela 7). Apesar da importância das micorrizas para o sistema solo-pastagem, a adubação com P nos dois anos experimentais e também a realização da calagem contribuíram para a diminuição da infestação das raízes por micorrizas, fato esperado, porque a infecção por micorrizas é abundante em solos pobres em fósforo e nitrogênio, assim como altos níveis de nutrientes são correlacionados ao baixo desenvolvimento de micorrizas.

A calagem realizada trouxe efeitos benéficos quanto aos teores de nutrientes no solo. No final de dois anos, com a calagem, houve aumento dos teores de Ca até a profundidade de $30 \mathrm{~cm}$, queda nos teores de alumínio até $10 \mathrm{~cm}$ e da saturação por alumínio até $30 \mathrm{~cm}$ para os dois experimentos.
Também houve aumento nos teores de Mg de até $10 \mathrm{~cm}$ para o experimento com supressão de $\mathrm{P}$ e de até $30 \mathrm{~cm}$ quando houve aplicação de $\mathrm{P}$ nos dois anos.

Houve aumento da saturação por bases de até $30 \mathrm{~cm}$ de profundidade, porém os valores estiveram aquém dos $70 \%$ pretendidos, situando-se entre 30,6 e 40,2 na camada de 0 a $5 \mathrm{~cm} ; 22,1$ e 24,3 na de 5 a $10 \mathrm{~cm}$; e 16,5 e 17,7 na de 10 a $30 \mathrm{~cm}$, para os experimentos com supressão ou não de $P$, respectivamente.

Houve efeito do tempo sobre os teores de nutrientes no solo. No experimento com supressão de adubação com P, houve redução nos teores de $\mathrm{Ca}, \mathrm{Mg}$ e V\%, na profundidade de 5 a $30 \mathrm{~cm}$, e nos teores de $\mathrm{K}, \mathrm{MO}$ e $\mathrm{P}$, até a profundidade de $30 \mathrm{~cm}$. Para o experimento com adubação fosfatada, nos dois anos houve queda nos teores de Ca e Mg na profundidade de 5 a $10 \mathrm{~cm}$, de $\mathrm{K}$ até $10 \mathrm{~cm}$ de profundidade, de $\mathrm{MO}$ até $30 \mathrm{~cm}$ de profundidade e de $\mathrm{P}$ e V\% na profundidade de 10 a $30 \mathrm{~cm}$ (Tabelas 9 a 12). Essa redução pode ser explicada pela maior extração de nutrientes no segundo ano, em decorrência da maior produção de forragem.

Apesar da queda do teor de nutrientes do primeiro para o segundo ano, os teores de nutrientes apresentados no segundo ano (após o término dos experimentos) foram maiores que os obtidos na pastagem degradada, como relatado anteriormente. Esse fato pode ser indicativo da recuperação parcial da fertilidade do solo, mas alerta para a possibilidade de a extração de nutrientes ser maior que a reposição realizada anualmente nesse projeto. 
Houve aumento somente no teor de S até a profundidade de $10 \mathrm{~cm}$ somente no experimento com supressão de $P$.

A fonte de fósforo apresentou interferência mínima nos teores de MO no solo, visto que, apenas no experimento com adubação fosfatada nos dois anos, o teor de MO foi maior quando se aplicou termofosfato em relação ao uso do superfosfato simples na profundidade de 0 a $5 \mathrm{~cm}$.

Houve efeito da interação tempo $\times$ fontes de $\mathrm{P}$ sobre $\mathrm{o}$ teor de P no solo. No primeiro ano, o superfosfato simples proporcionou maior teor de $\mathrm{P}$ que o supertriplo e o termofosfato para os dois experimentos, ao passo que, no

Tabela 6 - Teor de S na parte-aérea da Brachiaria brizantha cv. Marandu para o experimento com aplicação de P nos dois anos Table 6 - S S concentration in the shoot of Brachiaria brizantha cv. Marandu in the experiment with $P$ application in both years

\begin{tabular}{|c|c|c|}
\hline \multirow[t]{2}{*}{ Item } & \multicolumn{2}{|c|}{$\begin{array}{l}\text { Teor de } S(\mathrm{~g} / \mathrm{kg}) \\
S \text { content }(\mathrm{g} / \mathrm{kg})\end{array}$} \\
\hline & $\begin{array}{c}\text { Águas } \\
\text { Rainy season }\end{array}$ & $\begin{array}{c}\text { Seca } \\
\text { Dry season }\end{array}$ \\
\hline \multicolumn{3}{|l|}{ Calagem (Liming) } \\
\hline Com calagem (With liming) & $1,21 \mathrm{~ns}$ & $0,9 \mathrm{~ns}$ \\
\hline Sem calagem (Without liming) & $1,17 \mathrm{~ns}$ & $0,9 \mathrm{~ns}$ \\
\hline Superfosfato simples (Superphosphate) & $1,21 \mathrm{~ns}$ & $0,9 \mathrm{~ns}$ \\
\hline Superfosfato triplo (Triple superphosphate) & $1,16 \mathrm{~ns}$ & $1,0 \mathrm{~ns}$ \\
\hline Termofosf. magnesiano (Magnesium termophosphate) & $1,21 \mathrm{~ns}$ & $0,8 \mathrm{~ns}$ \\
\hline \multicolumn{3}{|l|}{ Tempo (Time) } \\
\hline Primeiro ano (First year) & $1,04 \mathrm{~b}$ & $0,7 \mathrm{~b}$ \\
\hline Segundo ano (Second year) & $1,34 \mathrm{a}$ & $1,1 \mathrm{a}$ \\
\hline Superfosfato simples (Superphosphate) & $1,10 \mathrm{~b}$ & - \\
\hline Superfosfato triplo (Triple termophosphate) & $1,15 \mathrm{ab}$ & - \\
\hline Termofosfato magnesiano (Magnesium termophosphate) & $1,25 \mathrm{ab}$ & - \\
\hline CV (\%) & 10,5 & 21,0 \\
\hline Testemunha degradada (Degraded control) & 1,3 & 0,89 \\
\hline Média (Mean) & 1,2 & 0,9 \\
\hline
\end{tabular}

Médias seguidas por diferentes letras, dentro da mesma coluna, são diferentes $(P<0,05)$ pelo teste Tukey.

Means followed by different letter, within column, are different $(P<0.05)$ by Tukey test.

Tabela 7 - Teor de Si na planta $(\mathrm{g} / \mathrm{kg})$ e porcentagem de infecção de micorrizas

Table 7 - Si concentration in the shoot and percentage micorrhizal infected roots

\begin{tabular}{|c|c|c|}
\hline Item & $\begin{array}{c}\text { Teor de Si }(\mathrm{g} / \mathrm{kg}) \\
\text { Si concentration }(\mathrm{g} / \mathrm{kg})\end{array}$ & $\begin{array}{c}\% \text { de raízes infectadas micorrizas } \\
\% \text { micorrhizal infected roots }\end{array}$ \\
\hline Fertilização com P - dois anos (Phosphorus fertilization - two years) & $0,53 \mathrm{~ns}$ & $48,3 b$ \\
\hline Fertilização com P - um ano (Phosphorus fertilization - one years) & $0,63 n s$ & $62,95 \mathrm{a}$ \\
\hline & \multicolumn{2}{|c|}{ Tratamento (Treatment) } \\
\hline Superfosfato simples (Superphosphate) & - & $63,5 a$ \\
\hline Superfosfato triplo (Triple superphosphate) & - & $59,72 \mathrm{ab}$ \\
\hline Calagem + superfosfato simples (Liming + superphosphate) & - & $54,78 \mathrm{ab}$ \\
\hline Calagem + superfosfato triplo (Liming + triple superphosphate) & - & $54,41 \mathrm{ab}$ \\
\hline Termofosfato magnesiano (Magnesium termophosphate) & - & $52,99 \mathrm{ab}$ \\
\hline Calagem + termofosfato magnesiano (Liming + Magnesium termophosphate) & - & $48,34 b$ \\
\hline Testemunha degradada ${ }^{1}$ (Degraded control) & 0,83 & 54,92 \\
\hline Média (Mean) & 0,58 & 55,63 \\
\hline $\mathrm{CV}(\%)$ primeiro ano (CV first year, \%) & 12,42 & 9,53 \\
\hline CV (\%) seguno ano (CV second year, \%) & 32,12 & 15,37 \\
\hline
\end{tabular}

Médias seguidas por diferentes letras, dentro da mesma coluna, são diferentes $(P<0,05)$ pelo teste Tukey.

Means followed by different letter, within column, are different $(P<0.05)$ by Tukey test.

${ }^{1}$ Média das testemunhas dos dois experimentos (Mean of controls from two experiment). 


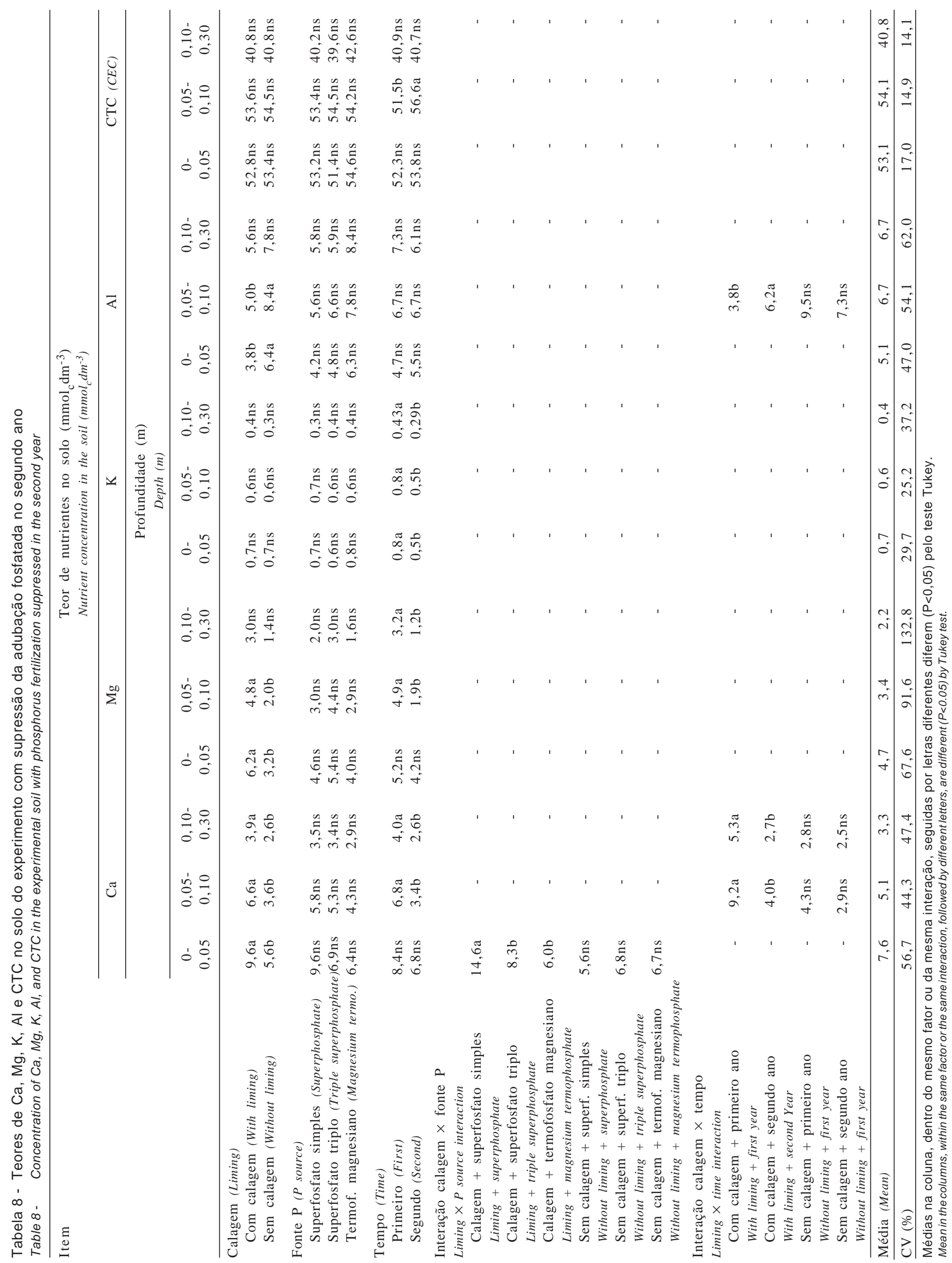




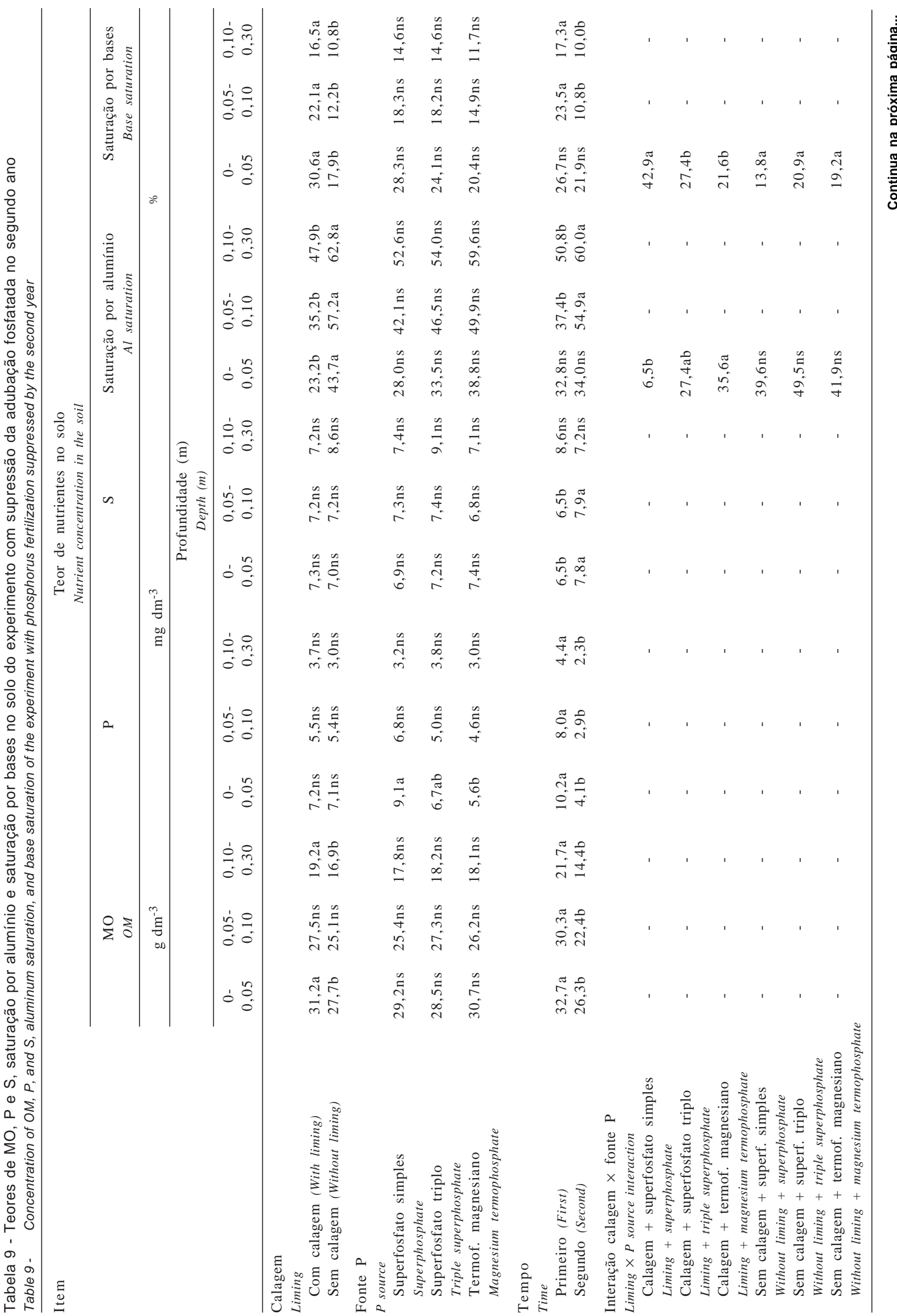




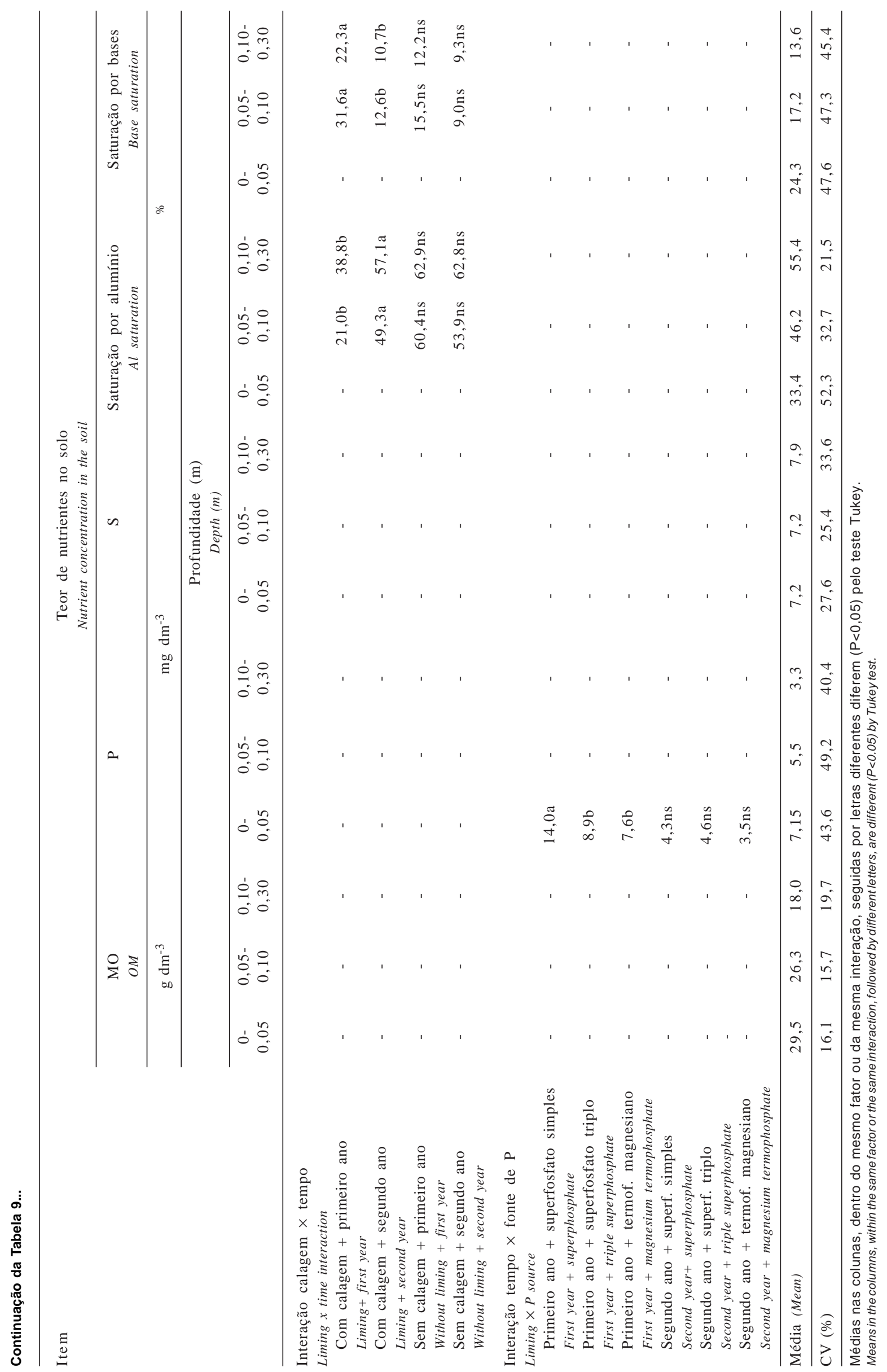




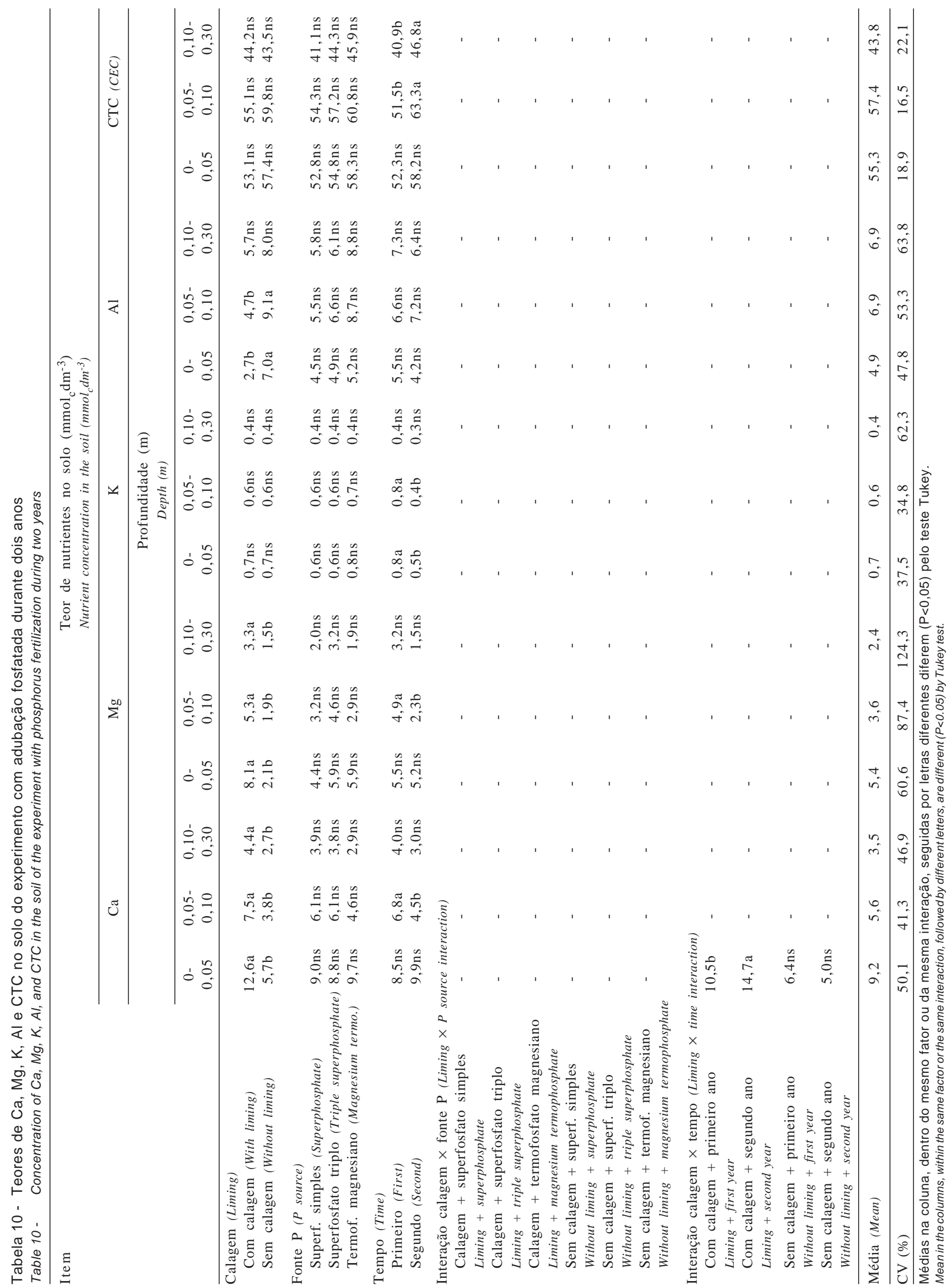




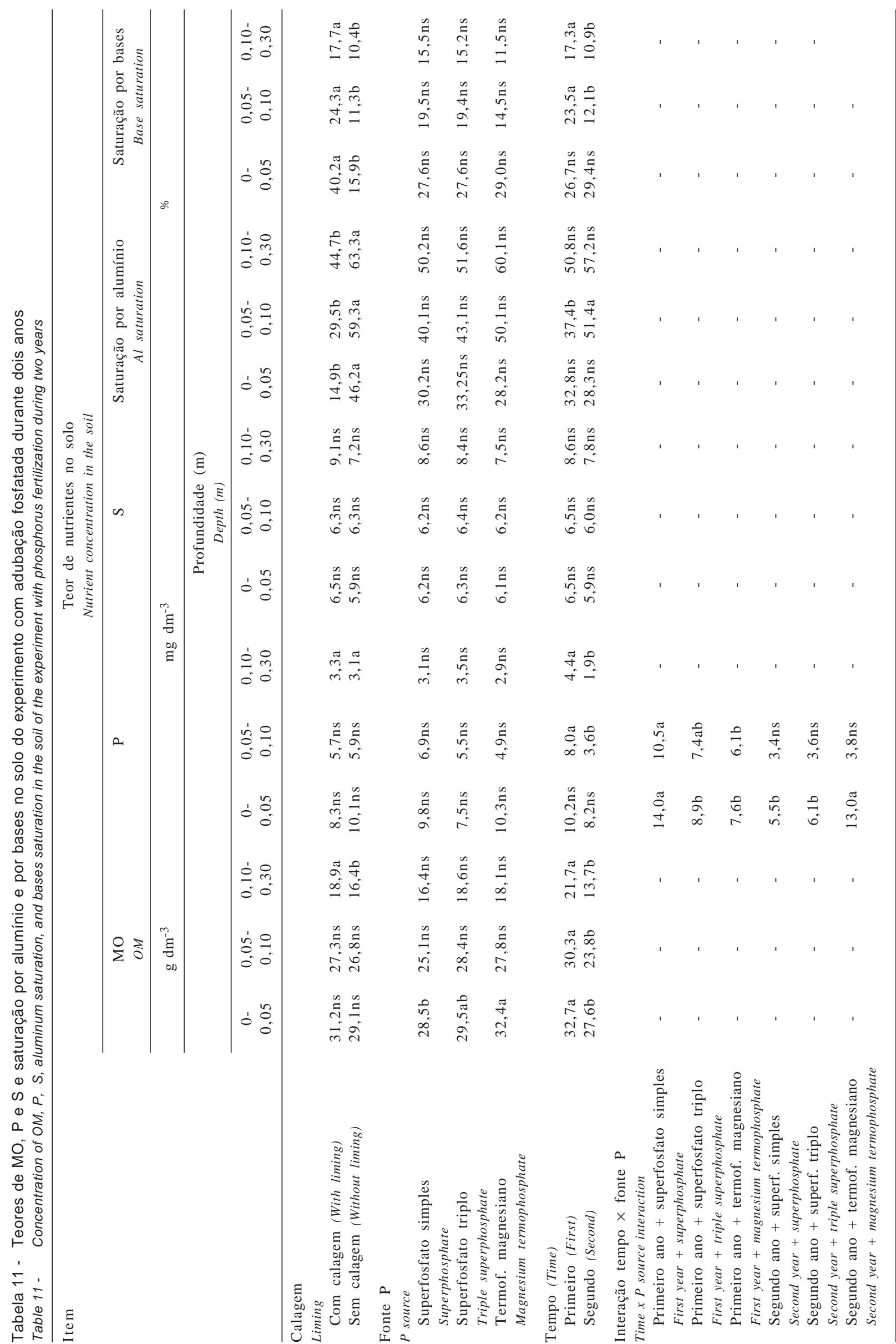




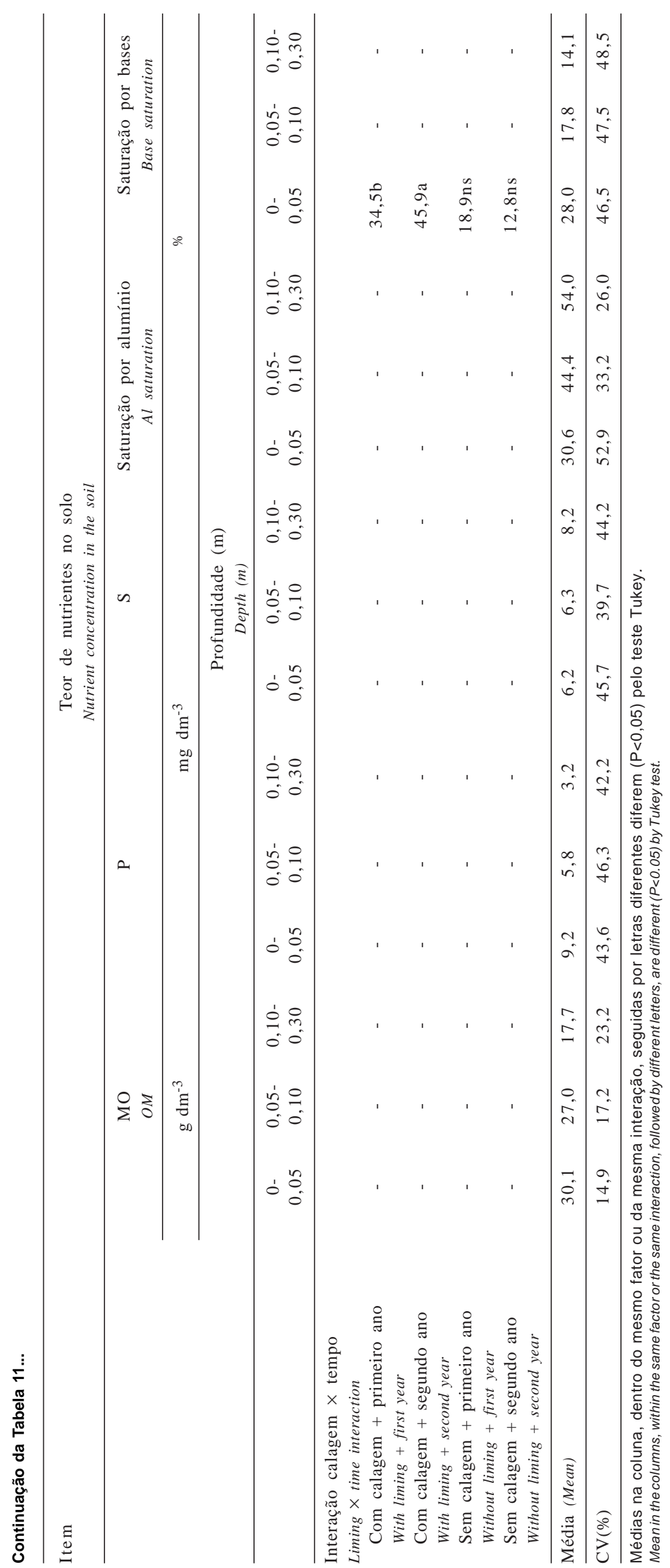


segundo ano, o termofosfato proporcionou maiores teores de $\mathrm{P}$ que as outras duas fontes no experimento com adubação fosfatada nos dois anos. Quando se suprimiu a adubação com P, as fontes não apresentaram diferença entre si.

\section{Conclusões}

Para áreas de solos pobres em $\mathrm{P}$, é interessante a associação de fontes prontamente solúveis (para garantir aumento de produção de forragem logo no início de manejo da pastagem) com termofosfato magnesiano (que apresentou efeito residual ao longo dos anos).

A produção de forragem foi maior no segundo ano em todas as condições avaliadas, fato esperado, por se tratar de fertilização em pastagem em recuperação. Os teores de $\mathrm{P}$ e S na forragem aumentaram do primeiro para o segundo ano, enquanto o teor de $\mathrm{N}$ diminuiu, alertando para a dose de $\mathrm{N}$ empregada. Além disso, os teores de nutrientes no solo diminuíram do primeiro para o segundo ano, fato que pode indicar maior extração de nutrientes que o reposto pela fertilização proposta neste experimento.

A calagem favoreceu a produção de forragem quando se suprimiu a adubação fosfatada no segundo ano. Também proporcionou aumentos nos teores de nutrientes e saturação por bases e provocou queda nos teores de alumínio no solo.

\section{Literatura Citada}

BÜLL, L.T.; LACERDA, S.; NAKAGAWA, J. Termofosfato: alterações em propriedades químicas em um Latossolo vermelhoescuro e eficiência agronômica. Bragantia, v.56, n.1, p.16979, 1997.
CAMARGO, O.A.; MONIZ, A.C.; JORGE, L.A. et al. Métodos de análise química, mineralógica e física do Instituto Agronômico de Campinas. Campinas: Instituto Agronômico, 1986. 94p. (Boletim Técnico, 106).

CUNHA, M.K.; SIEWERDT, L.; SILVEIRA JR., P. et al. Doses de nitrogênio e enxofre na produção e qualidade da forragem de campo natural de planossolo no Rio Grande do Sul. Revista Brasileira de Zootecnia, v.30, n.3, p.651-658, 2001.

GOEDERT, W.J.; LOBATO, E. Avaliação agronômica de fosfatos em solo de Cerrado. Revista Brasileira de Ciência do Solo, v.8, p.97-102, 1984.

LOPES, A.S. Solos sob "Cerrado": características, propriedades e manejo. 2.ed. Piracicaba: Potafos, 1984. 162p.

MOREIRA, A.; MALAVOLTA, E.; VIRGENS FILHO, A.C. et al. Avaliação da disponibilidade do fósforo no solo por métodos isotópico, químico e biológico. Scientia Agricola, v.54, n.1-2, p.78-84, 1997.

NAKAYAMA, L.H.I.; CACERES, N.T.; ALCARDE, J.C. et al. Eficiência relativa de fontes de fósforo de diferentes solubilidades na cultura do arroz. Scientia Agricola, v.55, n.2, p.183-90, 1998

OLIVEIRA. P.P.A.; TRIVELIN, P.C.O.; OLIVEIRA, W.S. et al. Fertilização com N e S na recuperação de pastagem de Brachiaria brizantha cv. Marandu. Revista Brasileira de Zootecnia, v.34, n.4, p.1121-1129, 2005.

OLIVEIRA, P.P.A.; BOARETTO, A.E.; TRIVELIN, P.C.O. et al. Liming and fertilization for restoring degraded Brachiaria decumbens pasture on sandy soil. Scientia Agricola, v.60, n.1, p.125-131, 2003.

OLIVEIRA, P.P.A.; CORSI, M. Eficiência da fertilização nitrogenada e sulfatada em pastagens. In: WORKSHOP SOBRE MANEJO DE FERTILIZANTES NITROGENADOS E SULFATADOS NA AGRICUlturA, 2001, Piracicaba. Palestras... Piracicaba: 2001. (CD-ROM).

ROSSI, C.; ANJOS, A.R.M.; CAMARGO, M.S. et al. Efeito residual de fertilizantes fosfatados para o arroz: avaliação do fósforo na planta e no solo por diferentes extratores. Scientia Agricola, v.56, n.1, p.39-46, 1999. 